\title{
Prohibitin: A Novel Molecular Player in KDEL Receptor Signalling
}

\author{
Monica Giannotta, ${ }^{1,2}$ Giorgia Fragassi, ${ }^{1}$ Antonio Tamburro, ${ }^{3}$ Capone Vanessa, \\ Alberto Luini, ${ }^{4}$ and Michele Sallese ${ }^{1}$ \\ ${ }^{1}$ Department of Cellular and Translational Pharmacology, Fondazione Mario Negri Sud, 66030 Santa Maria Imbaro, Italy \\ ${ }^{2}$ Department of Cell Biology \& Signalling, The FIRC Institute of Molecular Oncology (IFOM), 20139 Milan, Italy \\ ${ }^{3}$ Proteomic Core Facility, Fondazione Mario Negri Sud, 66030 Santa Maria Imbaro, Italy \\ ${ }^{4}$ Institute of Protein Biochemistry, National Research Council and Telethon Institute of Genetics and Medicine, 80131 Naples, Italy
}

Correspondence should be addressed to Michele Sallese; sallese@negrisud.it

Received 5 December 2014; Accepted 14 April 2015

Academic Editor: Christian Appenzeller-Herzog

\begin{abstract}
Copyright (C) 2015 Monica Giannotta et al. This is an open access article distributed under the Creative Commons Attribution License, which permits unrestricted use, distribution, and reproduction in any medium, provided the original work is properly cited.

The KDEL receptor (KDELR) is a seven-transmembrane-domain protein involved in retrograde transport of protein chaperones from the Golgi complex to the endoplasmic reticulum. Our recent findings have shown that the Golgi-localised KDELR acts as a functional G-protein-coupled receptor by binding to and activating Gs and Gq. These G proteins induce activation of PKA and Src and regulate retrograde and anterograde Golgi trafficking. Here we used an integrated coimmunoprecipitation and mass spectrometry approach to identify prohibitin-1 (PHB) as a KDELR interactor. PHB is a multifunctional protein that is involved in signal transduction, cell-cycle control, and stabilisation of mitochondrial proteins. We provide evidence that depletion of PHB induces intense membrane-trafficking activity at the ER-Golgi interface, as revealed by formation of GM130-positive Golgi tubules, and recruitment of p115, $\beta$-COP, and GBF1 to the Golgi complex. There is also massive recruitment of SEC31 to endoplasmicreticulum exit sites. Furthermore, absence of PHB decreases the levels of the Golgi-localised KDELR, thus preventing KDELRdependent activation of Golgi-Src and inhibiting Golgi-to-plasma-membrane transport of VSVG. We propose a model whereby in analogy to previous findings (e.g., the RAS-RAF signalling pathway), PHB can act as a signalling scaffold protein to assist in KDELR-dependent Src activation.
\end{abstract}

\section{Introduction}

Intracellular organelles maintain their homeostasis through the continuous exchange of proteins and lipids, which tend to intermix during membrane trafficking. The transport of cargoes from the endoplasmic reticulum (ER) to the Golgi complex involves temporary mislocalisation of ER-resident proteins into post-ER compartments. By virtue of their KDEL sequence, these ER proteins can bind to the KDEL receptor (KDELR) and are thence shuttled back to the ER. To date, three different genes have been identified in human that encode the closely related KDELRs: KDELR1, KDELR2, and KDELR3 [1-4].

The KDELR is an integral membrane protein with seven transmembrane domains [5]. The $\mathrm{N}$-terminal of the receptor faces the lumen of the organelles, while the C-terminal is in the cytosol $[6,7]$. In addition to the rescue of chaperones, the KDELR takes part in the regulation of the ER stress response, by modulation of the p38 mitogen-activated protein kinases (MAPKs) [8]. The KDELR also activates extracellular signalregulated kinases (ERKs) and autophagy, which contributes to the clearance of intracellularly aggregated mutant proteins, such as superoxide dismutase 1 (SOD1), $\alpha$-synuclein, and the pathological huntingtin [9]. Recently, we identified a novel signalling cascade that is activated by the KDELR at the Golgi complex [10, 11]. Here, the KDELR acts as a G-proteincoupled receptor (GPCR) and stimulates Gq, which, in turn, promotes the activation of the Src family kinases (SFKs) $[10,11]$. These active SFKs trigger a complex tyrosine phosphorylation cascade that controls membrane trafficking from the Golgi to the plasma membrane [10]. 
In the present study, while looking for novel KDELR interactors that might participate in the signal transduction of the KDELR, we identified prohibitin-1 (PHB). PHB is a member of an evolutionarily conserved family of proteins that includes PHB-2, stomatin, erlins, flotillins, and the bacterial protein HflK. These proteins share the stomatin/prohibitin/flotillin/HflK/C (SPFH) domain, which is also known as the PHB domain [12]. PHB-domain proteins are integral membrane proteins or are strongly associated with cell membranes via posttranslational modifications (i.e., acyl moieties) or via hydrophobic regions. These proteins have the tendency to oligomerise and to segregate into lipid rafts, which are specific membrane subdomains that are enriched in cholesterol and glycosphingolipids [12]. PHB-domain proteins are widely distributed in the different cellular organelles, including the mitochondria, the ER, the Golgi complex, the endosomes, and the plasma membrane [13-16].

$\mathrm{PHB}$ is a $30-\mathrm{kDa}$ protein with a single membrane spanning domain mainly localised in the inner mitochondrial membrane, where it functions as a chaperone and controls proteostasis of mitochondrial proteins $[17,18]$. PHB knockdown affects the organisation of the mitochondrial network, possibly by preventing membrane fusion, although it does not alter the mitochondrial membrane potential and the ATP generation system $[13,19]$. In addition to mitochondria, $\mathrm{PHB}$ is in the nucleus, where it modulates DNA transcription, and in the plasma membrane, where it modulates receptor signalling downstream of the insulin receptor and proteaseactivated receptor 1 (PAR1) $[13,16,20]$. Insulin promotes $P H B$ phosphorylation on Y114 and Y259, and via Akt on T258 $[21,22]$. These phosphorylations are required for the adaptor functions of PHB on RAS-dependent activation of RAF1/ERK signalling [16]. PHB carries out these tasks by physical association with AKT and RAF1. From a cell-biology standpoint, $\mathrm{PHB}$ can promote cancer cell growth and formation of metastasis in animal models $[16,19,23]$. Furthermore, the levels of $\mathrm{PHB}$ on the plasma membrane correlate with cancer outcome, highlighting the importance of $\mathrm{PHB}$ in cancer signalling [16].

In the present study, we have identified a KDELR-PHB complex and explored the functional role of $\mathrm{PHB}$ along the KDELR signalling pathway, as well as in its coordination of membrane trafficking. We provided evidence that $\mathrm{PHB}$ is required for KDELR-dependent SFKs activation, transport of cargo from the Golgi complex to the plasma membrane, and membrane trafficking between the Golgi complex and the ER.

\section{Results}

2.1. Signalling and Membrane Transport Machinery Proteins Coimmunoprecipitate with the KDELR. To elucidate the molecular events triggered by the KDELR in the regulation of membrane trafficking, we used a coimmunoprecipitation approach. The best antibody available against the endogenous KDELR recognizes an epitope sequence at the KDELR Ctail. As this region is believed to be involved in binding with KDELR interactors, to prevent any bias in our immunoprecipitation, we used a transfected epitope-tagged version of the KDELR [11]. Furthermore, as transfection efficiency can vary across different experiments, we decided to exploit HeLa cells stably transfected with myc-tagged KDELR (HeLa-myc cells), which were previously used to study interactions between the KDELR and ARF GAP1 [24]. Therefore, these HeLa-myc cells represent a good tool to investigate KDELR interactors.

Initially, we characterised this cell line to determine whether this stable transfection of the myc-tagged KDELR affects distribution of the endogenous KDELR, Golgi complex organisation, or membrane transport. Here, the intracellular distribution of the stably transfected myc-tagged KDELR was similar to that of endogenous KDELR, and their expression levels were also comparable (see Supplementary Figure S1 in Supplementary Material available online at http://dx.doi.org/10.1155/2015/319454). Also, the structure of the Golgi complex was not affected in the HeLa-myc cells, as assessed by GM130, mannosidase II and TGN46 staining (Supplementary Figure S1). The membrane-traffic efficiency was investigated using the temperature-sensitive mutant vesicular stomatitis virus $G$ glycoprotein (VSVG). This mutant VSVG is synchronisable according to temperature, and it has been widely used to assess protein folding and the efficiency of the secretory pathway [10]. At $40^{\circ} \mathrm{C}$, VSVG cannot fold completely in the ER, and consequently its exit from the ER is blocked (temperature-block). When the cells are then shifted to $32^{\circ} \mathrm{C}$ (temperature-block release), VSVG can fold and leave the ER, and in this way it is synchronously transported through the secretory pathway to the plasma membrane. The transport kinetics of VSVG in HeLa-myc cells was similar to that in wild-type HeLa cells (Supplementary Figure S2). In view of these data, we considered that the HeLa-myc cells represent a suitable model for coimmunoprecipitation experiments.

To determine whether the immunoprecipitation conditions were appropriate for coimmunoprecipitation of the KDELR with its interacting partners, we searched for proteins that should interact with the KDELR on the bases of previous studies, or that are components of the retrograde transport machinery. The HeLa-myc and control HeLa cells were lysed, and the proteins were immunoprecipitated using agaroseconjugated anti-c-myc antibodies. The immunoprecipitated proteins were analysed by Western blotting, which revealed the $\mathrm{Gs}$ and $\mathrm{Gq}$ subunits of the heterotrimeric $\mathrm{G}$ proteins $[11,25]$, and the $\beta$ subunit of the COPI coatomer complex (Supplementary Figure S3). These proteins were absent in the immunoprecipitate obtained from the wild-type control HeLa cell lines. These data indicated that the chosen cell model and experimental conditions are optimal to reveal KDELR interactors.

\subsection{Identification of KDELR Interactors by Mass Spectrometry.} To identify KDELR interactors, we carried out preparative coimmunoprecipitation of the KDELR from the control and HeLa-myc cells. The immunoprecipitated proteins were separated by two-dimensional gel electrophoresis, and then the gels were silver stained. Differentially immunoprecipitated proteins were excised, subjected to tryptic digestion, and analysed by matrix-assisted laser desorption/ionisation timeof-flight mass spectrometry (MALDI-TOF MS). The peptide masses obtained were matched to peptide mass databases 
using the ProFound and MASCOT software. Peptide matching and protein searches were performed by submitting the peptide mass lists to database searches on NCBInr and/or SWISS PROT, using the MASCOT and ProFound search engines.

This analysis identified PHB as a potential KDELR interactor. In view of our interest in the signalling functions of the KDELR, PHB was further investigated.

2.3. PHB Coimmunoprecipitates with the KDELR. To confirm that PHB is part of the KDELR interactome, HeLa-myc cells stably expressing the KDELR-myc chimera were subjected to coimmunoprecipitation using an agarose-conjugated antic-myc antibody, followed by Western blotting with an antiPHB antibody. This approach confirmed coprecipitation of PHB with the KDELR (Figure 1(a)). To exclude potential non-specific binding of $\mathrm{PHB}$ with the agarose resin, we performed the same immunoprecipitation from lysates of wild-type HeLa cells. Here, the PHB protein did not show any intrinsic interactions with the agarose-conjugated anti-c-myc antibody (Figure 1(a))

To further understand the KDELR-PHB association, we modulated the KDELR interaction with $\mathrm{PHB}$ by perturbing Golgi homeostasis using brefeldin A (BFA) [26]. The fungal metabolite BFA induces rapid and reversible disassembly of the Golgi stack into tubules and vesicles, which results in redistribution of the majority of Golgi membranes and enzymes into the ER, in a reversible manner. BFA treatment results in redistribution of the KDELR into a remnant of the ER-Golgi intermediate compartment. In this context, we examined whether this redistribution of the KDELR that is induced by BFA treatment affects the interaction of the KDELR with PHB. HeLa-myc cells were treated with $5 \mu \mathrm{g} / \mathrm{mL}$ BFA for $5 \mathrm{~min}$ and then subjected to coimmunoprecipitation using an agarose-conjugated anti-c-myc antibody, which was followed by Western blotting with an anti-PHB antibody. After this 5 min of BFA treatment the KDELR lost its interaction with $\mathrm{PHB}$ (Figure 1(b)). These data strengthen the specificity of this interaction between the KDELR and PHB. In addition, since BFA targets the Sec7-type GTP-exchange factors for ARF1, the KDELR-PHB interaction might be regulated by ARF.

Previous studies have demonstrated that PHB is mainly localised to the mitochondria, although it has also been reported to localise to the nucleus and the plasma membrane $[13,16,17,27]$. To support our coprecipitation data, we investigated whether minor amounts of $\mathrm{PHB}$ can localise to the Golgi complex. Endogenous PHB was labelled in COS7 cells and counterstained with the mitochondrial marker Mito-Tracker (Figure 2(a)) or GM130 as a Golgi marker (not shown). We confirmed that the majority of PHB was in the mitochondria, although the plasma membrane was also labelled, while it was difficult to reveal PHB on the Golgi complex. To better understand the relationships of $\mathrm{PHB}$ labelling with the KDELR and the Golgi complex, COS-7 cells were transfected with GFP-tagged PHB and myc-tagged KDELR. A minor fraction of PHB colocalised with the cis-Golgi marker GM130 and KDELR-GFP, indicating that the Golgi membranes can be targeted by PHB (Figures 2(b) and 2(c)).

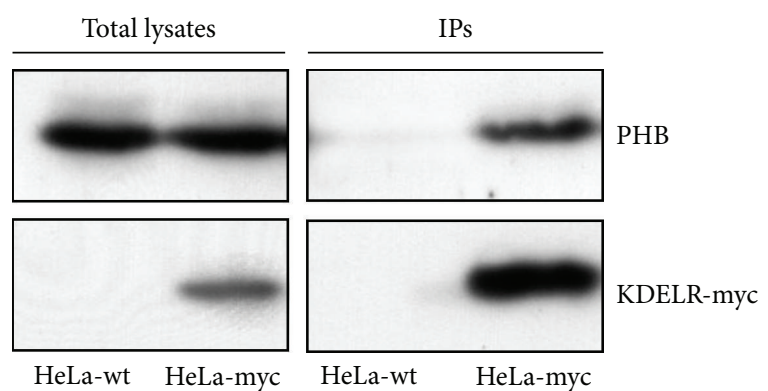

(a)
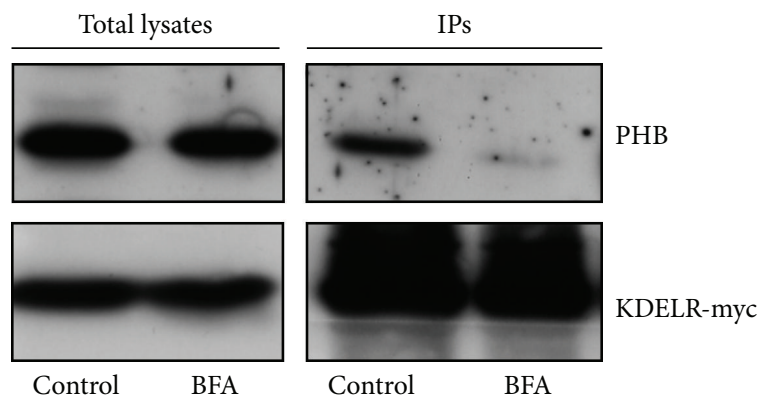

(b)

FIgURE 1: The KDELR-PHB interaction. (a) PHB coimmunoprecipitates with the KDELR. Protein from wild-type (HeLa-wt, control) and stably transfected KDELR-myc (HeLa-myc) HeLa cells were immunoprecipitated using anti-myc antibodies. The proteins from cell lysates (Total lysates) and immunoprecipitated (IPs) were separated by polyacrylamide gel electrophoresis and analysed by Western blotting for PHB and KDELR-myc. The images shown are representative of three independent experiments. (b) BFA treatment dissociates the KDELR-PHB complex. HeLa-myc cells were treated with vehicle (Control) or for $5 \mathrm{~min}$ with $5 \mu \mathrm{g} / \mathrm{mL} \mathrm{BFA}$ and the proteins were immunoprecipitated with anti-myc antibodies. The proteins from cell lysates (Total lysates) and immunoprecipitated (IPs) were separated by polyacrylamide gel electrophoresis and analysed by Western blotting for PHB and KDELR-myc, as indicated. The images shown are representative of two independent experiments.

\subsection{Functional Morphology of the Secretory Pathway in PHB-} Depleted Cells. To gain insight into the role of $\mathrm{PHB}$ at the Golgi complex, we carried out morphological analysis of the secretory pathway in cells under RNA interference for PHB. HeLa-myc cells were treated with $\mathrm{PHB}$ small-interfering (si)RNA, and PHB expression was analysed at various times. PHB was down-regulated by $70 \%$ already after $48 \mathrm{~h}$ of this RNA interference, and reached about $90 \%$ knock-down after $96 \mathrm{~h}$ (Figure 3(a)). This later time (i.e., 96h) was used for the morphological analysis. These PHB-interfered HeLa-myc cells were labelled for five key proteins that are localised at the ER-Golgi interface and are involved in anterograde and retrograde membrane trafficking. The Golgi matrix protein GM130 localises to the cis-Golgi. It is involved in Golgi stacking and membrane trafficking via tubular membranes from the cis-Golgi to the most distal region of the ER-Golgi intermediate compartment. The vesicle-tethering protein p115 is a GM130-interacting protein that is localised to the cis-Golgi and is involved in the transport of cargoes from the ER to 


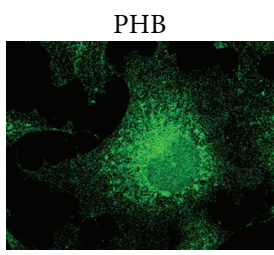

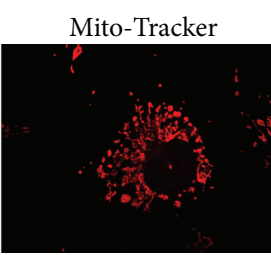

(a)
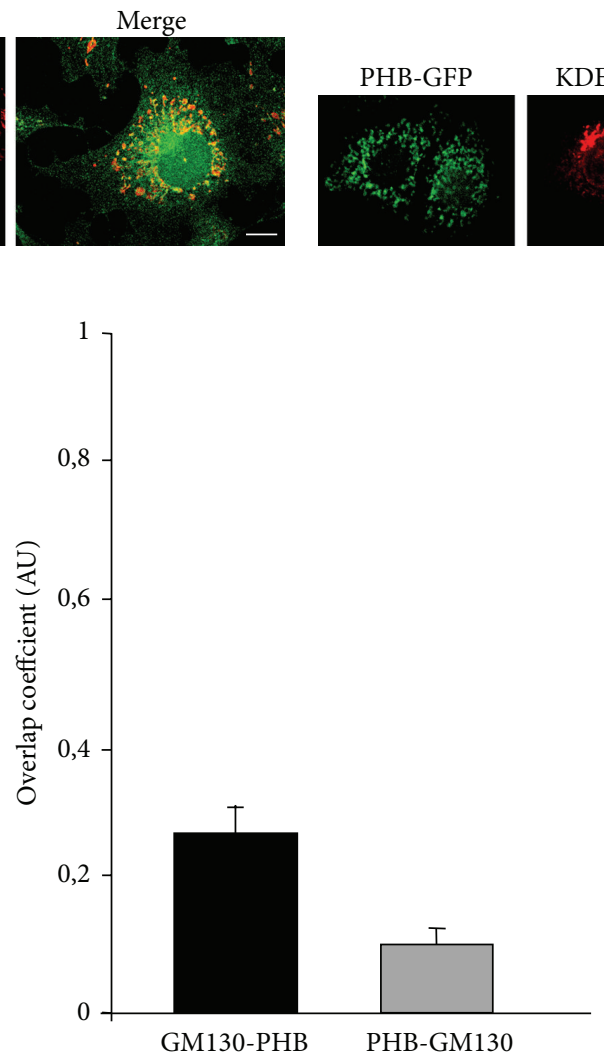
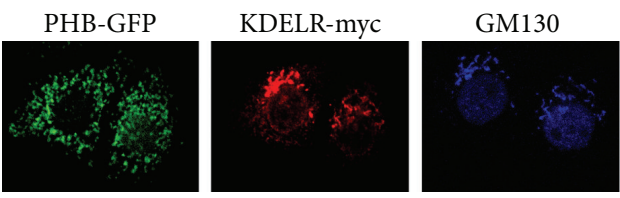

(b)

b)

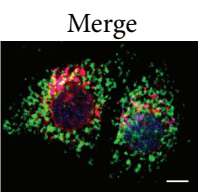

(c)

FIGURE 2: Intracellular distribution of PHB. (a) PHB mainly localises to the mitochondria. COS-7 cells were fixed, permeabilised, and stained for PHB (green) and Mito-Tracker (red). The merged image of green and red signals is also shown. (b) Colocalisation analysis of PHB and Golgi proteins. COS-7 cells were transiently transfected with GFP-tagged PHB and myc-tagged KDELR. The day after, the cells were fixed and stained for myc (red), and GM130 (blue). The merged image of the green (PHB-GFP), red and blue signals is also shown. (a, b) The images shown are representative of three independent experiments. Scale bars, $10 \mu \mathrm{m}$. (c) Quantification of PHB-GFP fluorescence colocalizing with GM130. The black bar indicates the extent of GM130 overlapping with PHB. The gray bar indicates the extent of PHB overlapping with GM130. Data are means of overlapping coefficient \pm SEM, representative of two independent experiments assessing at least 25 cells each. AU: arbitrary units.

the cis-Golgi. The coatomer protein complex-I (COPI) is a protein complex that coats newly forming membrane carriers (vesicles, tubules), and participates in intra-Golgi transport and retrograde Golgi-to-ER transport. $\beta$-COP is a component of the COPI complex, and it has been used to monitor the activity and distribution of COPI. Golgi BFA-resistant guanine nucleotide exchange factor $1 \mathrm{GBF} 1$ is an activator of the small GTPase ARF and is also a part of the COPI complex. COPII is a protein complex that coats newly forming membrane carriers (vesicles and tubules) that exit the ER. SEC31 is a component of COPII, and it has been used to monitor the activity and distribution of COPII.

Remarkably, the knock-down of PHB induced strong changes in the intracellular distribution of these markers, as compared to control (mock) cells (Figure 3(b)). Specifically, GM130 showed intense tubulation in about $25 \%$ of the interfered cells that might be indicative of a strong trafficking activity at the Golgi interface (Figure 3(b)). The amount of p115 recruited to the Golgi complex was increased, which also suggested stronger membrane trafficking activity (Figure 3(b)). $\beta$-COP immunofluorescence at the Golgi as well as on peripheral dots (i.e., transport carriers) was also increased (Figures 3(b) and 3(c)). GBF1 showed stronger staining in the central Golgi area, as well as of peripheral transport carriers, which were more numerous (Figure 3(b)). Similarly, there were many more SEC31-positive carriers, and these accumulated towards the central Golgi area (Figure 3(b)). Finally, we examined the expression levels of these proteins in control and PHB interfered cells. As shown in Figure 3(d) the amounts of GM130, p115, $\beta$-COP, GBF1 and SEC31 were not substantially affected by the knockdown of PHB indicating that the increased immunofluorescent staining is caused by an activation/recruitment of these proteins to the membranes.

Altogether, these findings suggest that removal of $\mathrm{PHB}$ stimulates membrane trafficking between the Golgi and the ER.

2.5. Knock-Down of PHB Interferes with KDELR-Dependent SFK Activation. Our group reported that KDELR stimulation triggers a signalling cascade that activates SFKs and controls membrane trafficking [10]. Here, we hypothesise a model 


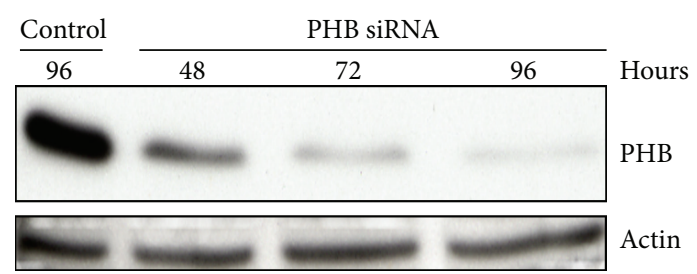

(a)
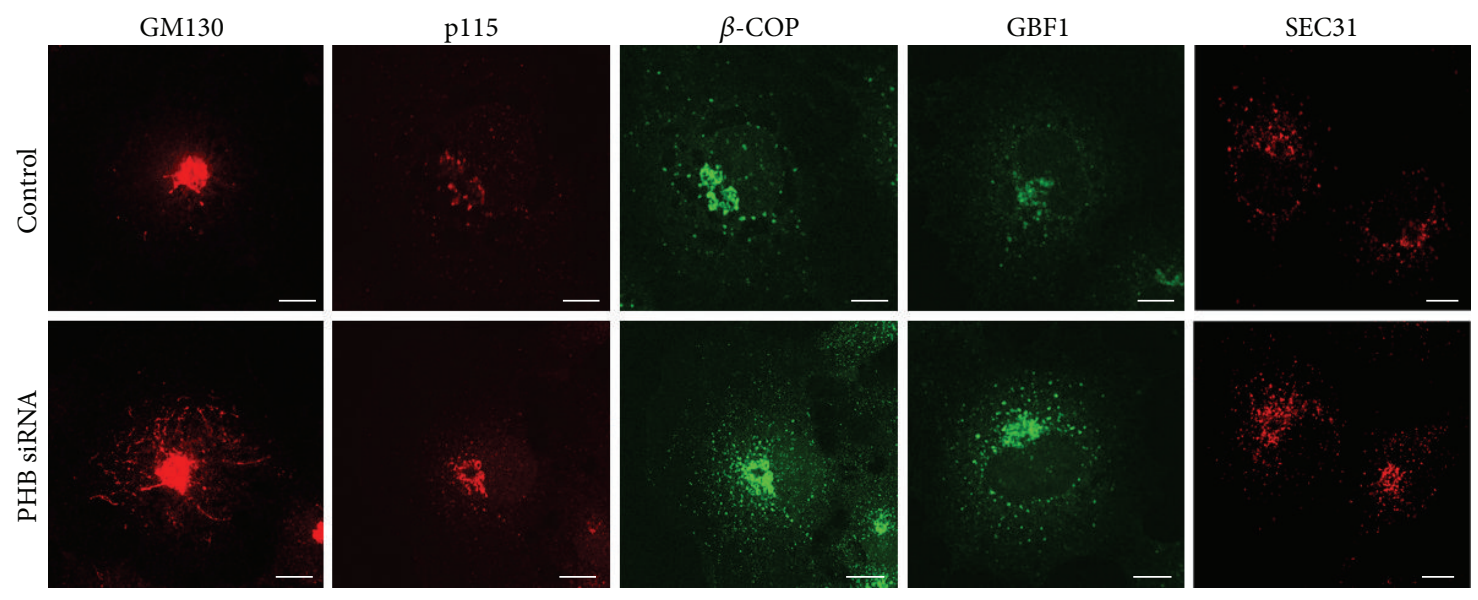

(b)

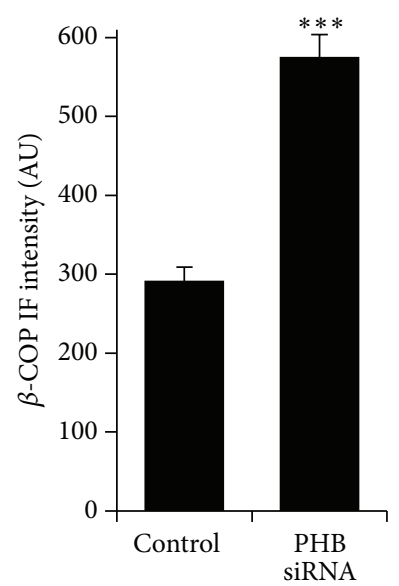

(c)

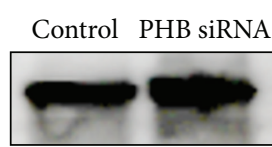

GM130

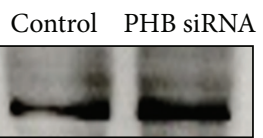

GBF1

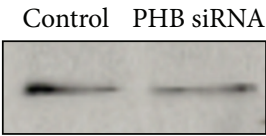

p115

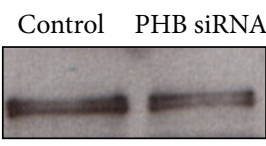

SEC31
Control PHB siRNA

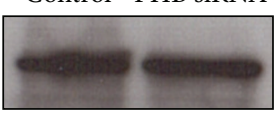

$\beta$-COP
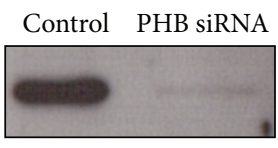

PHB

(d)

Figure 3: Effects of PHB knock-down on five proteins localised at the ER-Golgi interface. (a) Analysis of PHB knockdown efficiency. HeLamyc cells were treated with siRNAs against PHB (PHB siRNA) for the indicated times. Scrambled interfered cells (Control) are shown as reference. The cells were lysed, and the proteins were analysed by Western blotting for PHB expression levels. Actin was used as the loading control. (b) PHB knockdown affects the intracellular distribution of ER and Golgi proteins. Mock-interfered (Control) and PHB-interfered (PHB siRNA) COS-7 cells were fixed and stained for GM130, p115, $\beta$ subunit of the COPI coatomer complex ( $\beta$-COP), GBF1 and SEC31, as indicated. The images are representative of two independent experiments. Scale bars, $10 \mu \mathrm{m}$. (c) Quantification of $\beta$-COP immunofluorescence levels on the Golgi complex. Data are means \pm SEM of $\beta$-COP immunofluorescence from two independent experiments, with at least 25 cells quantified per experiment. ${ }^{* * *} p<0.001$ compared to control cells $(t$-test). AU: arbitrary units. (d) PHB knockdown does not affect the expression levels of ER and Golgi proteins. COS-7 cells treated as in B were lysed and their proteins analysed by Western blotting using antibodies to GM130, p115, $\beta$-COP, GBF1 and SEC31. The levels of PHB knockdown were investigated as a control.

where in an analogy with previous findings (the RAS-RAF pathway [19]), PHB can act as a signalling scaffold protein and assist in KDELR-dependent SFKs activation. To test this hypothesis, we determined the activation of the SFKs in PHB knocked-down cells.

Our previous study showed that a transport pulse of VSVG activates the KDELR, and in turn, the SFKs [10]. Thus,
PHB knocked-down HeLa-myc cells were infected with VSV, exposed to a pulse of VSVG traffic [10], and analysed for the activation of SFKs using Western blotting. The SFKs were activated in the controls and the mock-interfered cells, while their activation was prevented in the PHB knock-down cells (Figure 4(a)). In addition, with activation of the SFKs monitored by confocal immunofluorescence analysis, this 


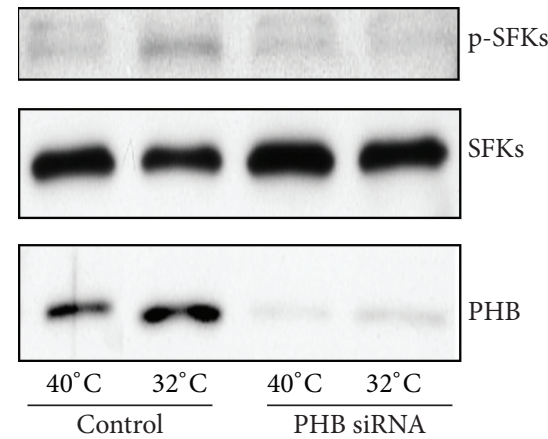

(a)
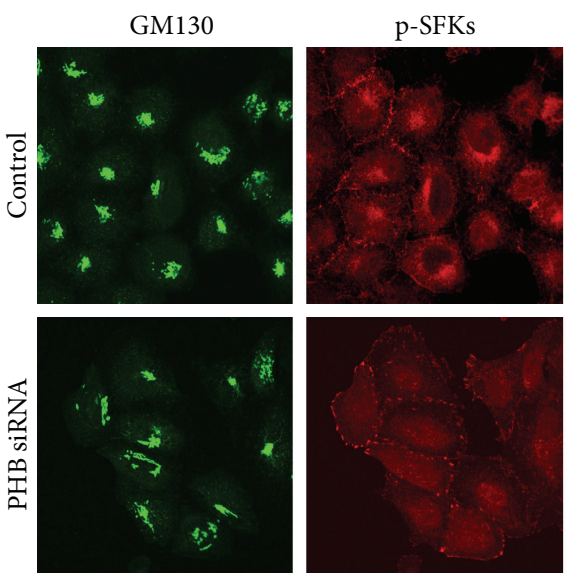

$T_{30}$ at $32^{\circ} \mathrm{C}$

(b)
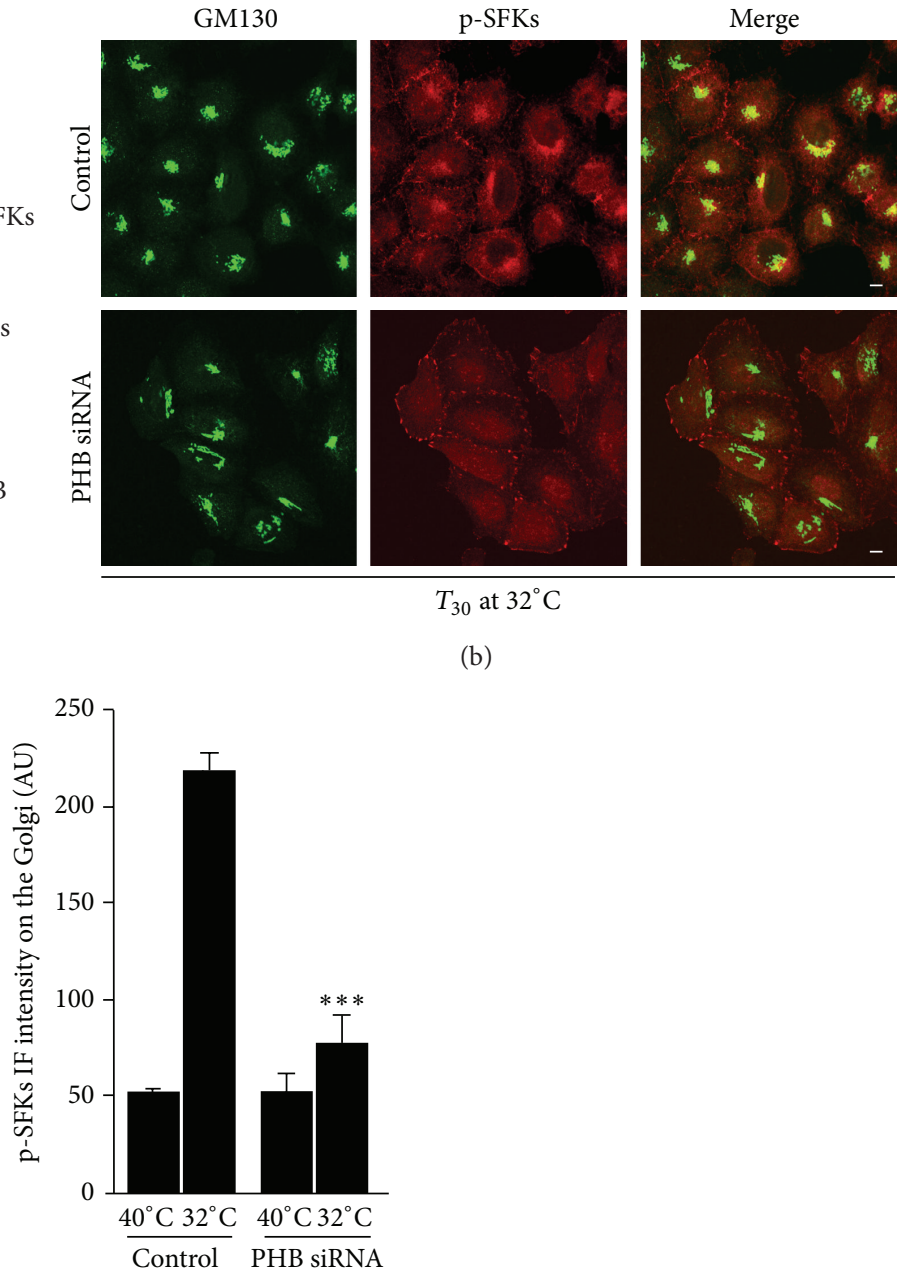

(c)

Figure 4: PHB knock-down hinders KDELR-dependent SFKs activation. (a) Depletion of PHB inhibits SFKs activation. HeLa-myc cells were treated with scrambled siRNAs (Control) or siRNAs against PHB (PHB siRNA) for $96 \mathrm{~h}$. After infection with VSV for 45 min, the cells were incubated at $40^{\circ} \mathrm{C}$ for $3 \mathrm{~h}$ (temperature block) and then shifted to $32^{\circ} \mathrm{C}$ for $30 \mathrm{~min}$ (block release). The cells were lysed and analysed by Western blotting for active phosphorylated SFKs (p-SFKs). The total SFKs (SFKs) was used as the loading control, while the knock-down levels were assessed with a PHB antibody. The images shown are representative of two independent experiments. (b) Depletion of PHB inhibits SFKs activation on the Golgi complex. HeLa-myc cells were treated as in (a). Following the 30 min of temperature-block release, the control cells and siRNA-treated cells were fixed and stained for GM130 (marker for Golgi area definition; green) and for active SFKs (p-SFKs; red); the merged images are also shown. Scale bars, $10 \mu \mathrm{m}$. (c) Quantification of p-SFKs immunofluorescence intensity on the Golgi complex of HeLa-myc cells treated as in (a). Data are means \pm SEM of three independent experiments, with at least 50 cells quantified per experiment. ${ }^{* * *} p<0.001$ compared to control cells at $32^{\circ} \mathrm{C}(t$-test).

confirmed strong inhibition of SFKs activation at the Golgi complex (Figures 4(b) and 4(c)). This suggested that PHB is required for activation of the SFKs downstream of the trafficpulse-dependent KDELR signalling cascade.

According to our published model, cargo proteins are transported from the ER to the Golgi complex together with KDEL proteins. These KDEL proteins can then bind to the KDELR, and activate the signalling cascade and the SFKs [10]. Thus, any impairment of the ER-to-Golgi traffic step might prevent SFKs activation.

To determine whether the SFKs activation and inhibition observed in PHB-depleted cells is caused by a transport problem, we monitored VSVG transport from the ER to the Golgi complex. Indeed, VSVG was efficiently transported to the Golgi complex in PHB-interfered HeLa-myc cells (Figure 5(a)).

2.6. Knock-Down of PHB Interferes with Golgi-to-PlasmaMembrane Transport of VSVG. SFKs inhibition results in the accumulation of VSVG in the Golgi complex, which prevents its arrival at the plasma membrane [10]. Here, we anticipated that in agreement with our previous data, by preventing SFKs activation, PHB knock-down would impair Golgi-to-plasmamembrane transport of VSVG.

HeLa-Myc cells with PHB knocked down were infected with VSV, and transport of VSVG was monitored $30 \mathrm{~min}$ 


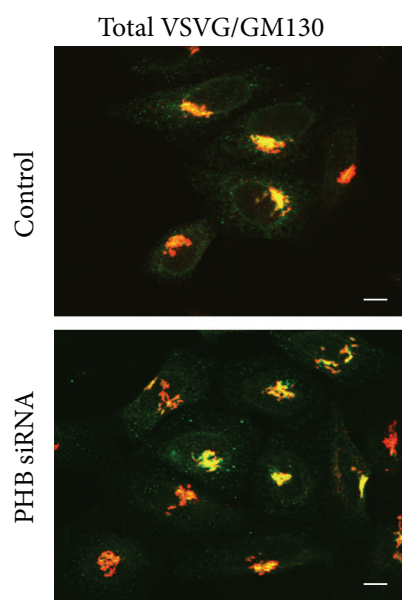

$T_{30}$ at $32^{\circ} \mathrm{C}$
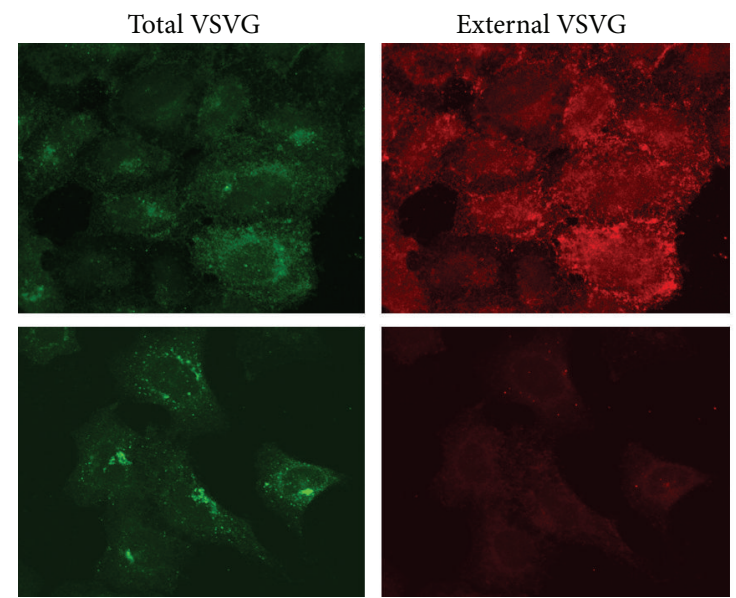

$T_{100}$ at $32^{\circ} \mathrm{C}$
External VSVG
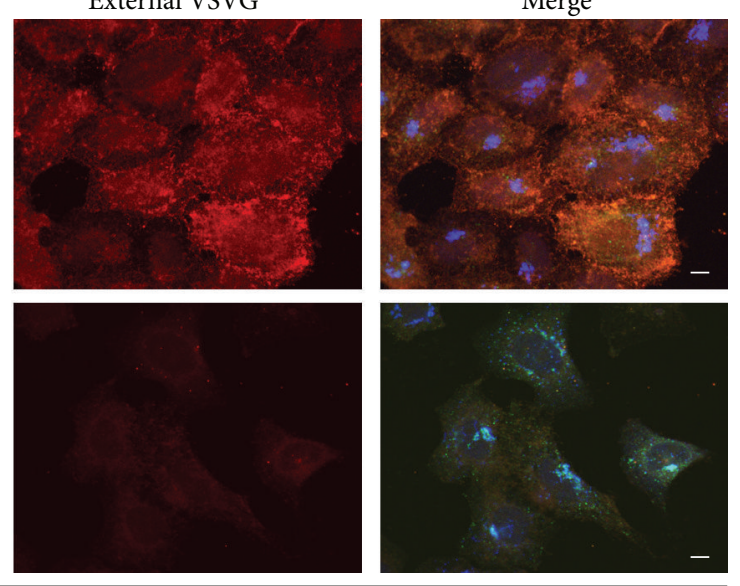

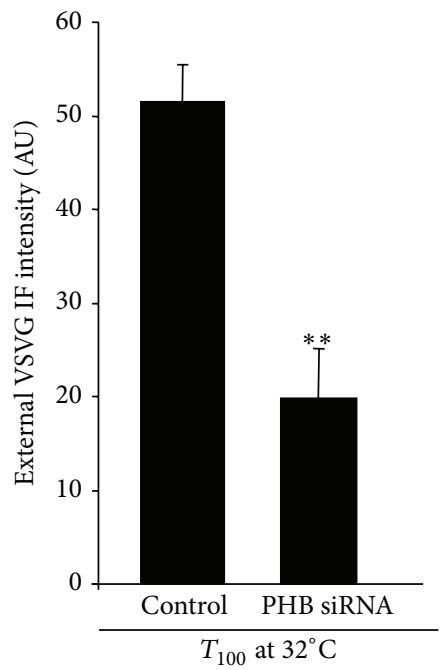

(b)

FIGURE 5: Trafficking of VSVG in PHB knock-down cells. (a) Depletion of PHB does not interfere with transport of VSVG to the Golgi complex, but it impairs VSVG arrival at the plasma membrane. HeLa-myc cells were treated with scrambled siRNAs (Control) or with siRNAs against PHB (PHB siRNA,) for $96 \mathrm{~h}$. After infection with VSV for $45 \mathrm{~min}$, the cells were incubated at $40^{\circ} \mathrm{C}$ for $3 \mathrm{~h}$ (temperature block) and then shifted to $32^{\circ} \mathrm{C}$ for the indicated times (temperature-block release). Left panels: The cells were fixed and stained for VSVG (green) and GM130 (marker for Golgi area definition, red); the merged images are also shown (Total VSVG/GM130). Right panels: Immunostaining for total VSVG (green), VSVG at the plasma membrane (revealed by an antibody against the extracellular domain of VSVG; External VSVG, red). The merged images shown include immunostaining for GM130 (blue). Scale bars, $10 \mu \mathrm{m}$. (b) Quantification of VSVG localised at the plasma membrane of HeLa-myc cells treated as in (a). Data are means \pm SEM of VSVG immunofluorescence on the plasma membrane, from three independent experiments, with at least 50 cells quantified per experiment. ${ }^{* *} p<0.05$ compared to control cells $(t$-test).

and $100 \mathrm{~min}$ after the release of the traffic block. At $30 \mathrm{~min}$, in the control (mock interfered) and PHB-interfered cells, VSVG was mainly localised in the Golgi complex. At $100 \mathrm{~min}$, VSVG had reached the plasma membrane in the controls, whereas it remained in the Golgi complex in PHB-interfered cells (Figure 5). This indicated that $\mathrm{PHB}$ participation in the KDELR-SFKs signalling pathway is also required for efficient Golgi-to-plasma-membrane transport. port of the KDELR. ER-resident proteins bearing the KDEL motif can reach post-ER compartments during membrane trafficking [28-32]. The KDELR cycles between the Golgi complex and the ER, and it binds and shuttles these proteins back to the ER. This triggers the KDELR signalling cascade. Thus any perturbation of the KDELR cycling might reduce the amount of KDELR in the Golgi compartment, and thus affect KDELR-mediated SFKs activation.

To understand how PHB knock-down might hinder KDELR-SFKs activation, we investigated the distribution of the KDELR in PHB-interfered HeLa cells. Immunofluorescence analysis of the endogenous KDELR showed major 
amounts in the Golgi complex and lesser amounts in the ER. PHB-depleted cells showed a striking reduction in the KDELR in the Golgi complex (Figures 6(a) and 6(b)). Western blot analysis of the KDELR ruled out the possibility that the low levels of Golgi-KDELR observed in PHB knockdown cells might be caused by a reduced KDELR expression or an increased degradation (Figure 6(c)).

These reduced levels of endogenous KDELR in the Golgi complex of PHB-depleted HeLa cells might be caused by an imbalance in the cycling of the KDELR between the ER and the Golgi complex. We investigated this possibility using an artificial chimeric protein constituted by the luminal domain of VSVG linked to the N-terminus of the KDELR (VSVGKDELR). Previous studies demonstrated that VSVG-KDELR accumulates in the Golgi complex when cells are incubated at $32^{\circ} \mathrm{C}$, while at $40^{\circ} \mathrm{C}$, VSVG-KDELR accumulates in the ER. Shifting the temperature of incubation of the cells from $32^{\circ} \mathrm{C}$ to $40^{\circ} \mathrm{C}$, it is possible to follow retrograde transport of the KDELR from the Golgi to the ER. PHB-interfered COS7 cells were transfected with the VSVG-KDELR chimera and incubated overnight at $32^{\circ} \mathrm{C}$. The day after, the cells were incubated at $40^{\circ} \mathrm{C}$ for $2 \mathrm{~h}$, and the localisation of the chimera was analysed by confocal microscopy. VSVGKDELR accumulated in the Golgi complex of controls and PHB-interfered cells upon incubation at $32^{\circ} \mathrm{C}$ (Figure 7 (a), upper panels). Two hours after the shift to $40^{\circ} \mathrm{C}$, in $90 \%$ of the PHB-interfered cells, the VSVG-KDELR chimera was relocated to the ER, while only $60 \%$ of the controls showed this phenotype (Figure 7(a), lower panels, Figure 7(b)).

This all indicates that PHB depletion affects KDELR homeostasis by accelerating its retrograde movement from the Golgi to the ER. The reduced levels of KDELR at the Golgi complex can contribute to decreased KDELR-dependent activation of SFKs in PHB knock-down cells.

\section{Discussion}

The KDELR belongs to the PQ-loop protein family [33], which is distantly related to the GPCR superfamily [34, 35], and resembles the GPCRs in topology and folds of its transmembrane helices $[34,35]$. KDELR-bound chaperones [5] activate a Golgi pool of the heterotrimeric G proteins $\mathrm{Gq}$ and Gs. Gs activates a signalling cascade at the cisGolgi, which results in activation of retrograde membrane transport [25], while Gq acts by inducing the activation of the SFKs, which phosphorylate a number of proteins, and allows anterograde traffic [10].

In the present study, to uncover the molecular players involved in the KDELR signal-transduction machinery, we searched for interactors of the KDELR using a coimmunoprecipitation and mass spectrometry approach. We identified PHB among the proteins that coimmunoprecipitated with the KDELR from HeLa cells. The KDELR-PHB complex was validated by modulation of their interactions upon BFA treatment. BFA inhibits the guanine-nucleotide exchange factors on ADP-ribosylation factor (ARF-GEFs), thus resulting in inactivation of ARF and loss of the KDELR-PHB interaction.
This suggests that the KDELR-PHB complex relies on a functional ARF1.

To date, intracellular $\mathrm{PHB}$ has been reported in the mitochondria and nucleus and at the plasma membrane but not in the ER or the Golgi complex, while the KDELR cycles between the ER and the Golgi $[13,29]$. In the present study we provided evidences that a minor fraction of $\mathrm{PHB}$ can localise to the Golgi complex.

However, to better support this novel relationship between the KDELR and PHB, we carried out a database analysis, with a search for any $\mathrm{PHB}$ interactors that have a well-established localisation to or function in the ER or the Golgi complex. Remarkably, PHB interacts genetically with the following yeast proteins: ARV1, an integral membrane protein that cycles between the ER and the Golgi complex and is involved in sphingolipid transport [36]; ERG5, a desaturase that is resident in the ER and is involved in ergosterol biosynthesis [36]; MMM1, which is an integral component of the ER membrane and part of the ER-mitochondria encounter structure (ERMES) [37]; SAC1, which is a phosphatidylinositol phosphate phosphatase that is an integral membrane protein and that cycles between the ER and the Golgi complex, to regulate protein trafficking [38]; and SCT1, which is an integral ER-membrane protein with a glycerol 3-phosphate/dihydroxyacetone phosphate acyltransferase activity [39]. Note that SCT1 interacts genetically with several ER-to-Golgi trafficking proteins, including the GET complex. The GET complex interacts with the yeast HDEL receptor (the yeast orthologue of the mammalian KDELR) in the retrieval of ER chaperones from the Golgi complex to the ER [40]. These genetic interaction data were obtained from the Saccharomyces Genome Database (http://www .yeastgenome.org/).

Furthermore, the yeast PHB protein has been detected in complexes with: ERP1, which is a member of the p24 family proteins and a component of the KDELR functional machinery [41]; MNN9, MNN10 and MNN11, which are components of the Golgi mannosyltransferase complex [42]; ANP1, which is an integral membrane protein of the cis-Golgi and a component of the alpha-1,6 mannosyltransferase complex [42]; and PMR1, which is an integral P-type ATPase of the Golgi membrane that can transport $\mathrm{Ca}^{2+} / \mathrm{Mn}^{2+}$ ions into the Golgi complex [43]. These data were also obtained from the Saccharomyces Genome Database (http://www.yeastgenome.org/). Finally, the $\alpha$ subunit of the human COPI complex has been identified in a complex with PHB (http:// bioinfow.dep.usal.es/apid/index.htm).

These numerous relationships among PHB and components of the ER and Golgi include proteins that are strictly related to the KDELR (e.g., p24 proteins and COPI subunits), and they strongly support the presence of $\mathrm{PHB}$ in these organelles, and its functional relationship with the KDELR.

PHB has an important role in the signalling pathway triggered by the RAS oncogene [13]. Indeed, PHB is required for the activation of RAF1 kinase downstream of RAS, and thus for cell growth [13]. According to the common model, PHB acts as a scaffold to productively direct the RAS-RAF1 interaction [19]. Remarkably, rocaglamides that target PHB impair 

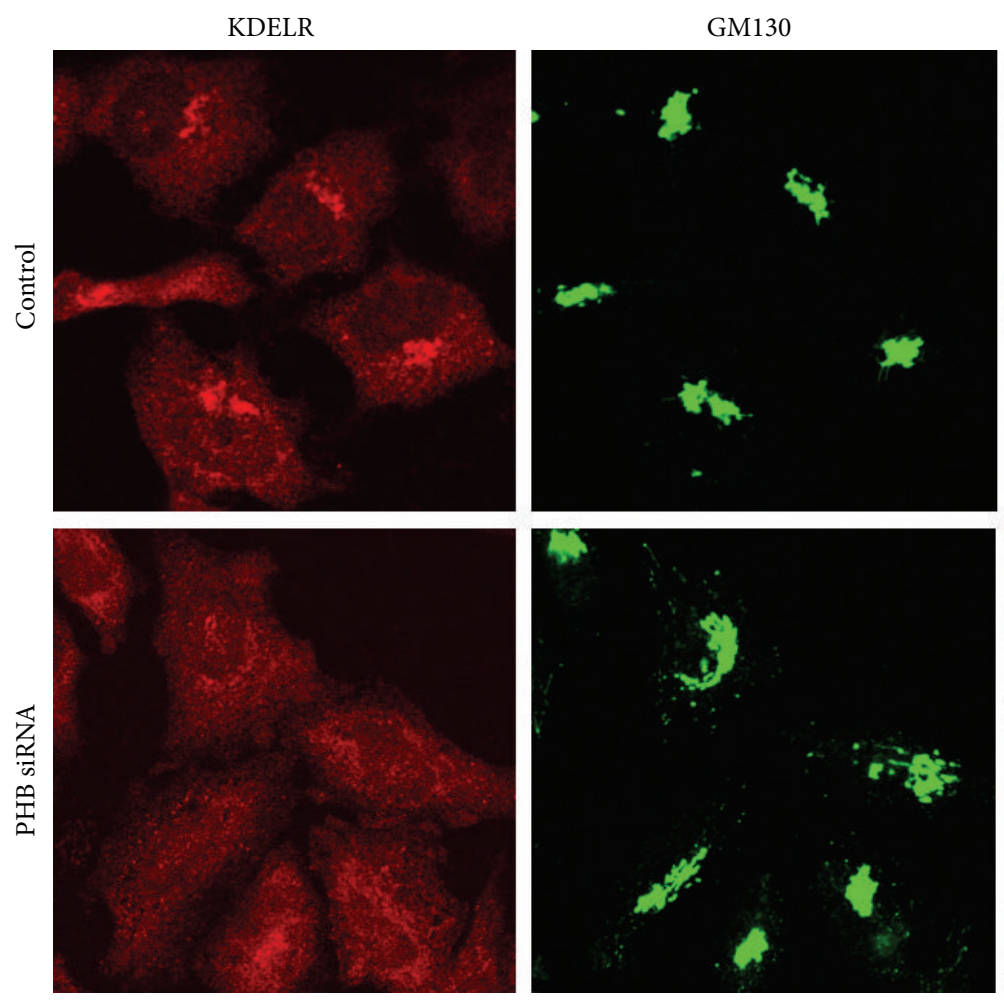

(a)
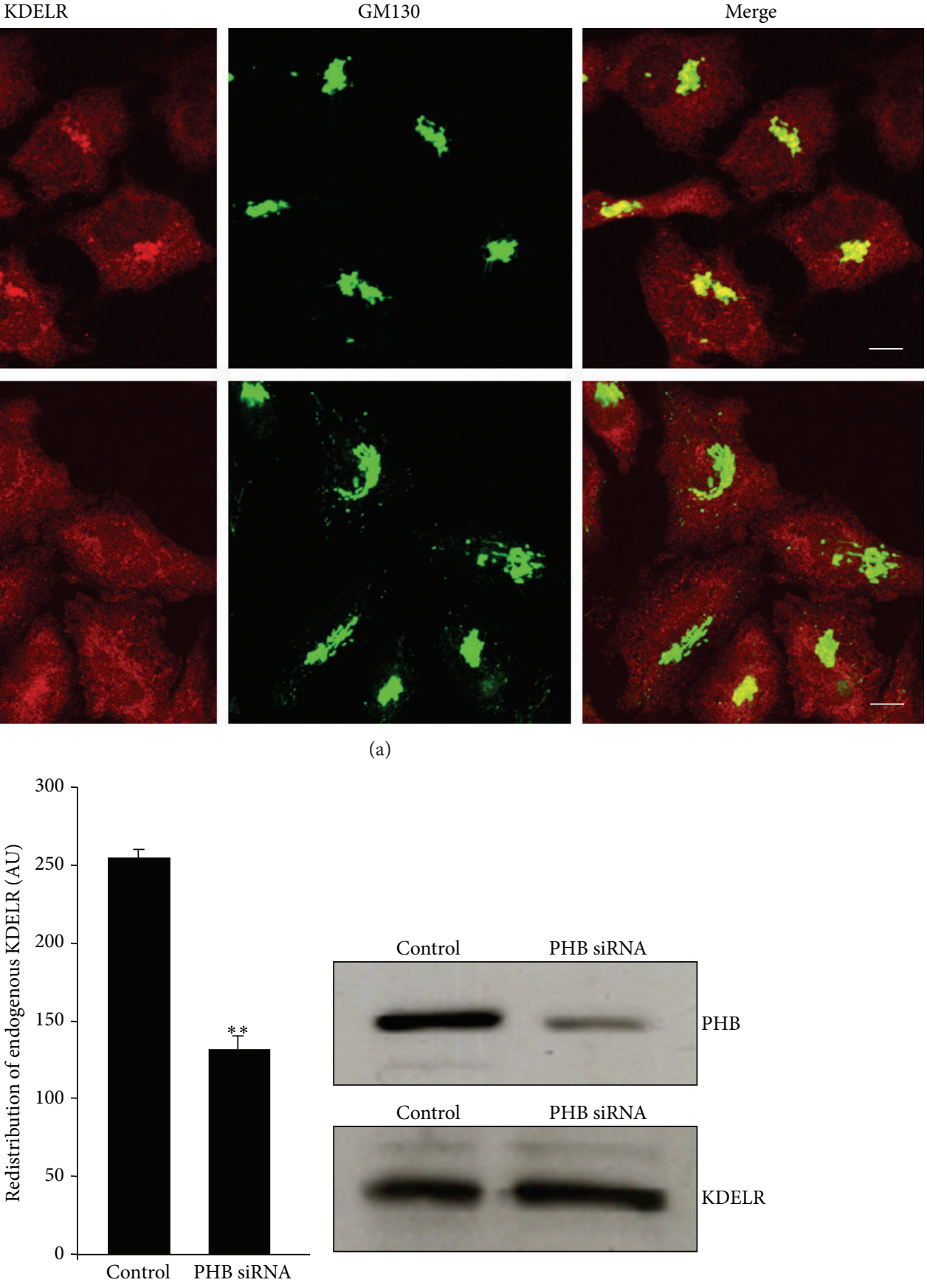

(b)

(c)

FIGURE 6: Intracellular distribution of endogenous KDELR in PHB knock-down cells. (a) KDELR redistributes from the Golgi in PHBdepleted cells. HeLa cells were treated with scrambled siRNAs (Control) or with siRNAs against PHB (PHB siRNA,) for 96 h. The cells were fixed and stained for KDELR (red) and GM130 (marker for Golgi area definition, green); the merged images are also shown. Scale bars, $10 \mu \mathrm{m}$. (b) Quantification of KDELR in the Golgi area of HeLa cells treated as in (a). Data are means \pm SEM for KDELR immunofluorescence on the Golgi, from three independent experiments, with at least 50 cells quantified per experiment. ${ }^{* * *} p<0.001$ compared to control cells $(t$-test). (c) PHB knockdown does not affect the expression levels of KDELR. HeLa cells treated as in (a) were lysed, and their proteins analysed by Western blotting using antibodies to KDELR. The levels of PHB knockdown were investigated as a control. 

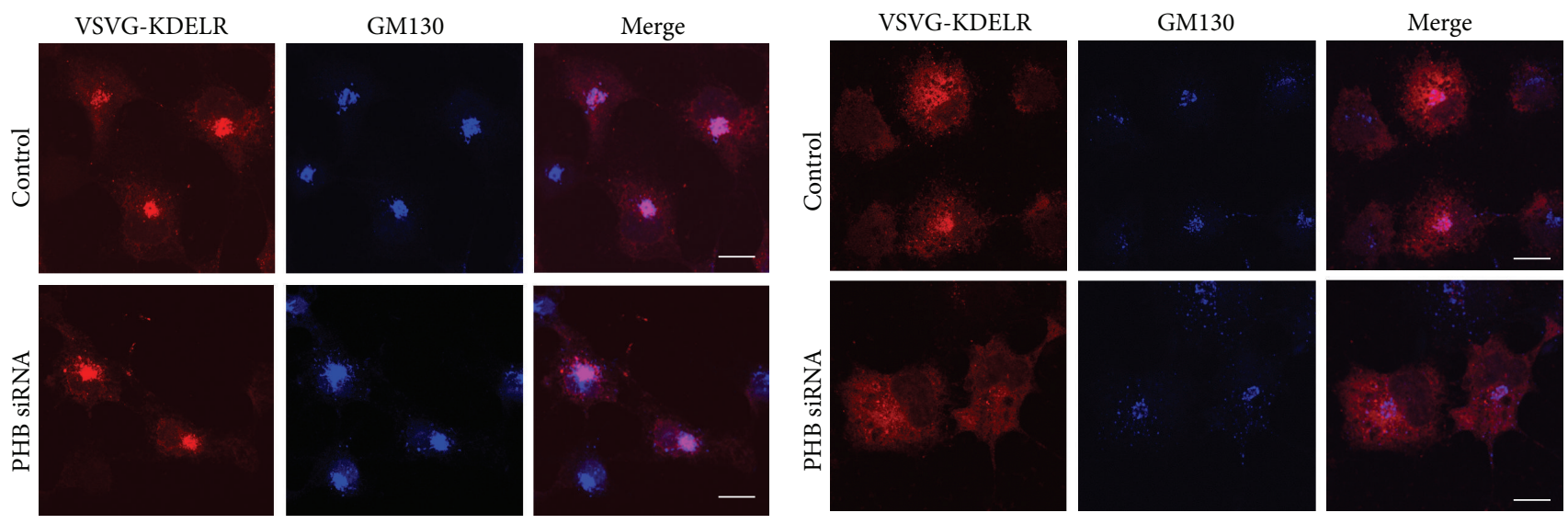

$T_{0}$ at $32^{\circ} \mathrm{C}$

(a)

$T_{2 \mathrm{~h}}$ at $40^{\circ} \mathrm{C}$

(b)

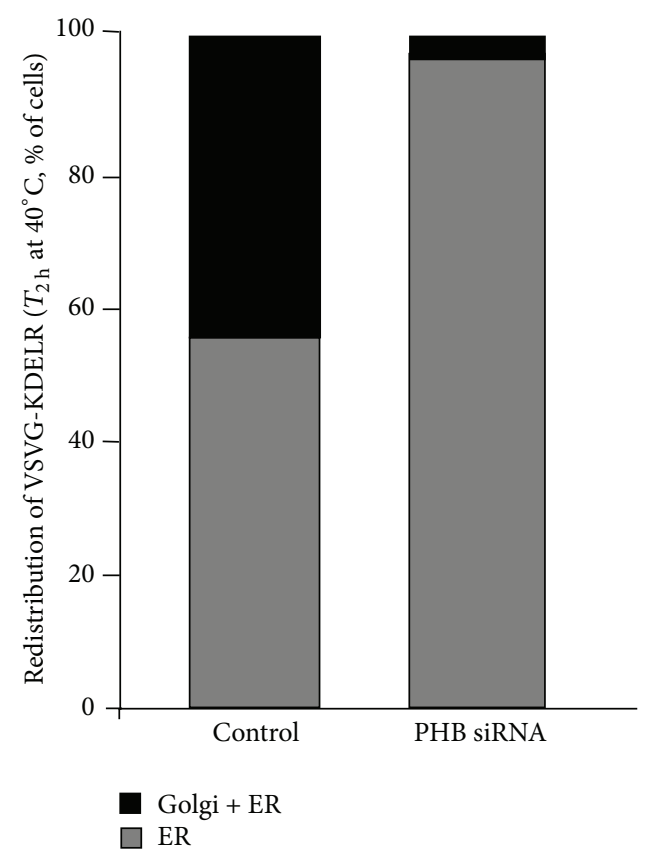

(c)

FIGURE 7: The intracellular dynamics of VSVG-KDELR chimera are affected by PHB knock-down. (a, b) The VSVG-KDELR chimera redistributes towards the ER in PHB-depleted cells. COS-7 cells were treated with scrambled siRNAs (Control) and with siRNAs against PHB (PHB siRNA,) for $48 \mathrm{~h}$, transfected for the VSVG-KDELR chimera, incubated overnight at $32^{\circ} \mathrm{C}$, and fixed (a), or following the incubation at $32^{\circ} \mathrm{C}$, the cells were further incubated at $40^{\circ} \mathrm{C}$ for $2 \mathrm{~h}$, and fixed (b). The cells were stained for the VSVG-KDELR chimera (red) and GM130 (marker for Golgi area definition, blue); the merged images are also shown. Scale bars, $10 \mu \mathrm{m}$. (c) Quantification of the KDELR in the Golgi and ER, or exclusively in the ER of COS-7 cells treated as in (b). Data are means \pm SEM of three independent experiments, with at least 50 cells quantified per experiment. ${ }^{* *} p<0.05$ compared to control cells $(t$-test).

the RAS-RAF1 interaction, and consequently prevent cancercell growth [44]. Furthermore, a recent study has demonstrated that PHB interacts and regulates the localisation and signalling of the PAR1 GPCR [20].

Here, we have reported that the knock-down of PHB mislocalises the KDELR (a functional GPCR [11]) and inhibits KDELR signalling, as for RAS-RAF signalling. In analogy to previous findings, we suggest that $\mathrm{PHB}$ acts as a scaffold to retain the KDELR in the appropriate cis-Golgi location and to allow activation of the SFKs.

Finally, in agreement with our previous data that showed that inhibition of KDELR-SFKs signalling impairs the transport of VSVG from the Golgi complex to the plasma membrane [10], the present study indicates that PHB knock-down 
interferes with KDELR-SFK activation thus leading to VSVG accumulation in the Golgi complex, which prevents it from reaching the plasma membrane.

\section{Materials and Methods}

4.1. Antibodies. The following antibodies were used: rabbit anti-c-myc polyclonal (Santa Cruz); rabbit anti-PHB polyclonal (NeoMarkers, Fremont CA, USA); mouse anti- $\beta$-COP monoclonal (Affinity BioReagents, Golden CO, USA); rabbit anti-lysozyme polyclonal (Chemicon); rabbit anti-p-SFKs polyclonal ( ${\mathrm{p}-\mathrm{Tyr}^{418}}^{41}$ ) (BioSource, CA, USA); rabbit anti-SFKs polyclonal (Santa Cruz Biotechnology); mouse anti-GM130 monoclonal and mouse anti-GBF1 monoclonal (Transduction Laboratories, Lexington, KY, USA); the mouse P5D4 anti-VSVG monoclonal (Sigma Aldrich); and rabbit VSVG luminal domain polyclonal (A. De Matteis), Rabbit p115 [45] and SEC31 were kindly provided by G. Di Tullio. Secondary antibodies were Alexa 488-, Alexa 546- (Molecular Probes, OR, USA), and Cy3-conjugated (Sigma-Aldrich).

\subsection{Cell Handling and Transport Synchronization Protocols}

Cell Handling. Human HeLa cells were maintained in Dulbecco's modified Eagle's medium supplemented with $10 \%$ foetal calf serum, $2 \mathrm{mM}$ L-glutamine, $100 \mu \mathrm{g} / \mathrm{mL}$ streptomycin sulphate, and 100 units/mL penicillin G (Gibco BRL, $\mathrm{UK}$ ), at $37^{\circ} \mathrm{C}$ in a humidified $5 \% \mathrm{CO}_{2}$ /air atmosphere. HeLa cells stably transfected with the human myc-tagged KDELR (HeLa-myc cells) were kindly provided by W. Hsu.

Transfections. The cells were transfected with Fugene 6 (Roche, Basel, Switzerland) according to the manufacturer instructions.

RNA Interference. The cells were transfected with Lipofectamine (Thermo Fisher Scientific Inc.), according to manufacturer instructions. PHB siRNA LQ-010530-00 (Dharmacon, Denver, Co., USA).

VSV Infection. The cells were infected with VSV as previously described (Mironov et al., 2001).

Transport Pulse Protocols. The VSVG transport pulses were as previously described (Mironov et al., 2001). Cycloheximide (Sigma Aldrich, WI, USA) was added at $50 \mu \mathrm{g} / \mathrm{mL}$ at the temperature shift.

4.3. Protein Analysis. Following the transport protocol, the cells were washed three times with ice-cold PBS and harvested immediately in lysis buffer (1\% Triton X-100, $20 \mathrm{mM}$ Tris-HCl, pH 8.0, $150 \mathrm{mM} \mathrm{NaCl}, 1 \mathrm{mg} / \mathrm{mL} \mathrm{Na} \mathrm{VO}_{4}, 5 \mathrm{mM}$ PMSF, $5 \mu \mathrm{g} / \mathrm{mL}$ each leupeptin, aprotinin, pepstatin), at $4^{\circ} \mathrm{C}$. The cell lysates were centrifuged at $15,000 \times \mathrm{g}$ for $5 \mathrm{~min}$ at $4^{\circ} \mathrm{C}$, to pellet and remove the nuclei. The postnuclear supernatant was immediately processed for SDS-PAGE and Western blotting. Of note, this separation of the postnuclear supernatant from the nuclei can be crucial for the detection of tyrosine phosphorylation.
4.4. Coimmunoprecipitation. To prepare total cell lysates, cells $\left(10^{7} / 150-\mathrm{mm}\right.$ plate $)$ were cooled on ice, washed with icecold $0.9 \% \mathrm{NaCl}$ (3 times) (Diaco, Italy), scraped, and lysed with $1.8 \mathrm{~mL}$ ice-cold lysis buffer (50 mM Tris- $\mathrm{HCl}, \mathrm{pH} 7.4$, $150 \mathrm{mM} \mathrm{NaCl}, 2 \mathrm{mM} \mathrm{MgCl}$, 1 mM EDTA, $1 \mathrm{mM} \beta$-mercaptoethanol, 1\% Triton or $15 \mathrm{mM}$ CHAPS (Sigma Aldrich) and a cocktail of protease inhibitors (Roche)). Subsequently, the total lysates were passed through a syringe needle (15 times) and incubated on a rotating wheel for $1.5 \mathrm{~h}$ at $4^{\circ} \mathrm{C}$. The lysates were then cleared by centrifugation at $14,000 \mathrm{rpm}$ for $15 \mathrm{~min}$. The supernatants (4-6 mg protein) were incubated overnight with agarose beads coupled to rabbit polyclonal cmyc antibody $(50 \mu \mathrm{L} / \mathrm{mg})$ (Santa Cruz Biotechnology). The settled beads were extensively washed with lysis buffer, and the bound protein was eluted 10 times with $0.1 \mathrm{M}$ ammonium hydroxide, $\mathrm{pH}$ 11. The eluted samples were dialysed against $500 \mathrm{mM}$ ammonium hydroxide, $\mathrm{pH} 11$, overnight at $4^{\circ} \mathrm{C}$, and then concentrated by lyophilisation.

4.5. Two-Dimensional Gel Electrophoresis. The lyophilised immunoprecipitated proteins were resuspended in rehydration buffer (5 M urea, $2 \mathrm{M}$ thiourea, 2\% CHAPS, 2\% Zwittergent, $40 \mathrm{mM}$ dithiothreitol (Sigma Aldrich), and 1\% IPG buffer (Amersham)). Proteins were separated by isoelectric focusing using an IPGphor apparatus (Amersham). In-gel rehydration was carried out on immobilised 13-cm IPG strips with a broad $\mathrm{pI}$ range: $\mathrm{pH}$ 3-10 linear gradient (Amersham). The optimised isoelectric focusing conditions were $20^{\circ} \mathrm{C}$, $50 \mu \mathrm{A} /$ strip: Step 1, rehydration at $30 \mathrm{~V}$ for $12 \mathrm{~h}$; Step 2, gradient to $1000 \mathrm{~V}$ for $10 \mathrm{~h}$; Step 3, step-n-hold $1000 \mathrm{~V}$ for $1 \mathrm{~h}$; Step 4 , gradient $8000 \mathrm{~V}$ for $1 \mathrm{~h}$; Step 5, step-n-hold $8000 \mathrm{~V}$ for $3 \mathrm{~h}$; for a total of $34360 \mathrm{~V} / \mathrm{h}$.

For the second dimension, the IPG strips were equilibrated for $15 \mathrm{~min}$ in $6 \mathrm{M}$ urea, $50 \mathrm{mM}$ Tris- $\mathrm{HCl}, \mathrm{pH} 8.8,30 \%$ glycerol, $2 \%$ SDS, $1 \%$ dithiothreitol, and for $15 \mathrm{~min}$ in $6 \mathrm{M}$ urea, 50 mM Tris-HCl, pH 8.8, 30\% glycerol, 2\% SDS, $100 \mathrm{mM}$ iodoacetamide. Proteins were separated using 12.5\% SDSPAGE, following standard protocols, and revealed with massspectrometry compatible silver staining.

4.6. Matrix-Assisted Laser Desorption/Ionization Time-ofFlight Mass Spectrometry. Protein bands were excised from the SDS-PAGE and placed in $0.5 \mathrm{~mL}$ microcentrifuge tubes (Eppendorf; Hamburg, Germany). After washing, the cysteines were reduced and alkylated with iodoacetamide [46]. The samples were digested with sequencing-grade modified trypsin (Promega, Madison, WI, USA) in $40 \mathrm{mM}$ ammonium bicarbonate at $37^{\circ} \mathrm{C}$ overnight, under slight shaking on a thermomixer. The reaction was stopped with $\mathrm{H}_{2} \mathrm{O} / 0.1 \%$ trifluoroacetic acid at $30^{\circ} \mathrm{C}$, for $15 \mathrm{~min}$. The resulting tryptic peptides were extracted, desalted with ZipTip $\mathrm{C}_{18}$ columns (Millipore Corp., Bedford, MA), directly eluted, and crystallised in a saturated solution of $\alpha$-cyano- 4 -hydroxy-cinnamic acid in $50 \%(\mathrm{v} / \mathrm{v})$ acetonitrile $/ \mathrm{H}_{2} \mathrm{O}$.

The samples were then spotted onto stainless steel MALDI sample target plates, and the peptide mass spectra were obtained by MALDI TOF MS (Reflex IV; Bruker Daltonics, Bremen, Germany), with a nitrogen laser and 
an emission wavelength of $337 \mathrm{~nm}$. The mass spectra were acquired in positive-ion reflectron mode with delayed extraction and $20 \mathrm{kV}$ acceleration voltage. External calibration was performed for each measurement, using a mixture of seven standard peptides (average mass accuracy, $>20 \mathrm{ppm}$ ). All of the mass spectra were acquired using a minimum number of 250 laser shots. The spectra were internally calibrated with trypsin autolysis products. Peptide matching and protein searches were performed through submission of the peptide mass lists to database searches (NCBInr and/or SWISS PROT), using the Mascot and ProFound search engines.

\subsection{Fluorescence Immunostaining and Confocal Microscopy.} The cells were grown to subconfluent density on glass coverslips for $24 \mathrm{~h}$ and then washed with PBS. Following fixing in $4 \%$ paraformaldehyde (Sigma Aldrich) for $10 \mathrm{~min}$ at room temperature, they were incubated in blocking solution $(0.05 \%$ saponin, $0.5 \%$ bovine serum albumin, $50 \mathrm{mM} \mathrm{NH}_{4} \mathrm{Cl}$; Sigma Aldrich) in PBS for $30 \mathrm{~min}$ at room temperature. The cells were subsequently incubated with the specified antibodies diluted in blocking solution, for 2-3 h at room temperature, or overnight at $4^{\circ} \mathrm{C}$. After incubation with the primary antibody, the cells were washed three times in PBS and incubated with a fluorescent conjugated anti-IgG secondary antibody for $1 \mathrm{~h}$ at room temperature. For the triple labelling (rabbit/mouse/sheep), Alexa 488-conjugated anti-rabbit or antimouse antibodies raised in chicken were used (rather than in goat), to avoid possible cross-reactions. The cells were finally examined under a confocal microscope (Zeiss LSM 510; Zeiss, Thornwood, NY, USA). The quantification of fluorescence signals was as follows. The area of interest was delineated manually and the fluorescence intensity was quantified using the LSM510-3.2 software (Zeiss). To assess the colocalization we removed the background immunofluorescence and used the colocalization functions of the LSM510-3.2 software (Zeiss).

\section{Conflict of Interests}

The authors declare that they have no competing financial interests.

\section{Acknowledgments}

The authors would like to thank the AIRC (Italy) for financial support. This study was supported by AIRC Grant no. IG 11652 to Michele Sallese. The authors also thank Chris Berrie for language editing of the paper.

\section{References}

[1] M. J. Lewis and H. R. B. Pelham, "A human homologue of the yeast HDEL receptor," Nature, vol. 348, no. 6297, pp. 162-163, 1990.

[2] M. J. Lewis and H. R. B. Pelham, "Sequence of a second human KDEL receptor," Journal of Molecular Biology, vol. 226, no. 4, pp. 913-916, 1992.
[3] V. W. Hsu, N. Shah, and R. D. Klausner, "A brefeldin A-like phenotype is induced by the overexpression of a human ERD-2-like protein, ELP-1," Cell, vol. 69, no. 4, pp. 625-635, 1992.

[4] J. E. Collins, C. L. Wright, C. A. Edwards et al., "A genome annotation-driven approach to cloning the human ORFeome," Genome Biology, vol. 5, no. 10, p. R84, 2004.

[5] J. C. Semenza, K. G. Hardwick, N. Dean, and H. R. B. Pelham, "ERD2, a yeast gene required for the receptor-mediated retrieval of luminal ER proteins from the secretory pathway," Cell, vol. 61, no. 7, pp. 1349-1357, 1990.

[6] A. A. Scheel and H. R. B. Pelham, "Identification of amino acids in the binding pocket of the human KDEL receptor," The Journal of Biological Chemistry, vol. 273, no. 4, pp. 2467-2472, 1998.

[7] F. M. Townsley, D. W. Wilson, and H. R. B. Pelham, "Mutational analysis of the human KDEL receptor: distinct structural requirements for Golgi retention, ligand binding and retrograde transport," The EMBO Journal, vol. 12, no. 7, pp. 2821-2829, 1993.

[8] K. Yamamoto, H. Hamada, H. Shinkai, Y. Kohno, H. Koseki, and T. Aoe, "The KDEL receptor modulates the endoplasmic reticulum stress response through mitogen-activated protein kinase signaling cascades," The Journal of Biological Chemistry, vol. 278, no. 36, pp. 34525-34532, 2003.

[9] P. Wang, B. Li, L. Zhou, E. Fei, and G. Wang, "The KDEL receptor induces autophagy to promote the clearance of neurodegenerative disease-related proteins," Neuroscience, vol. 190, pp. 43-55, 2011.

[10] T. Pulvirenti, M. Giannotta, M. Capestrano et al., "A trafficactivated Golgi-based signalling circuit coordinates the secretory pathway," Nature Cell Biology, vol. 10, no. 8, pp. 912-922, 2008.

[11] M. Giannotta, C. Ruggiero, M. Grossi et al., “The KDEL receptor couples to $\mathrm{G} \alpha_{q / 11}$ to activate Src kinases and regulate transport through the Golgi," The EMBO Journal, vol. 31, no. 13, pp. 28692881, 2012.

[12] D. T. Browman, M. B. Hoegg, and S. M. Robbins, "The SPFH domain-containing proteins: more than lipid raft markers," Trends in Cell Biology, vol. 17, no. 8, pp. 394-402, 2007.

[13] I. Chowdhury, W. E. Thompson, and K. Thomas, "Prohibitins role in cellular survival through Ras-Raf-MEK-ERK pathway," Journal of Cellular Physiology, vol. 229, no. 8, pp. 998-1004, 2014.

[14] S. Mishra, S. R. Ande, and B. L. G. Nyomba, "The role of prohibitin in cell signaling," The FEBS Journal, vol. 277, no. 19, pp. 3937-3946, 2010.

[15] I. Chowdhury, W. Xu, J. K. Stiles et al., "Apoptosis of rat granulosa cells after staurosporine and serum withdrawal is suppressed by adenovirus-directed overexpression of prohibitin," Endocrinology, vol. 148, no. 1, pp. 206-217, 2007.

[16] C.-F. Chiu, M.-Y. Ho, J.-M. Peng et al., "Raf activation by Ras and promotion of cellular metastasis require phosphorylation of prohibitin in the raft domain of the plasma membrane," Oncogene, vol. 32, no. 6, pp. 777-787, 2013.

[17] L. G. J. Nijtmans, M. Artal Sanz, L. A. Grivell, and P. J. Coates, "The mitochondrial PHB complex: roles in mitochondrial respiratory complex assembly, ageing and degenerative disease," Cellular and Molecular Life Sciences, vol. 59, no. 1, pp. 143-155, 2002.

[18] V. Emerson, D. Holtkotte, T. Pfeiffer et al., "Identification of the cellular prohibitin 1/prohibitin 2 heterodimer as an interaction partner of the C-terminal cytoplasmic domain of the HIV-1 glycoprotein," Journal of Virology, vol. 84, no. 3, pp. 1355-1365, 2010. 
[19] K. Rajalingam and T. Rudel, "Ras-Raf signaling needs prohibitin," Cell Cycle, vol. 4, no. 11, pp. 1503-1505, 2005.

[20] Y.-J. Wang, X.-L. Guo, S.-A. Li et al., "Prohibitin is involved in the activated internalization and degradation of proteaseactivated receptor 1," Biochimica et Biophysica Acta: Molecular Cell Research, vol. 1843, no. 7, pp. 1393-1401, 2014.

[21] E. K.-H. Han, T. McGonigal, C. Butler, V. L. Giranda, and Y. Luo, "Characterization of Akt overexpression in MiaPaCa-2 cells: prohibitin is an Akt substrate both in vitro and in cells," Anticancer Research, vol. 28, no. 2, pp. 957-963, 2008.

[22] S. R. Ande, Y. Gu, B. L. G. Nyomba, and S. Mishra, "Insulin induced phosphorylation of prohibitin at tyrosine114 recruits Shp1," Biochimica et Biophysica Acta-Molecular Cell Research, vol. 1793, no. 8, pp. 1372-1378, 2009.

[23] V. Sánchez-Quiles, E. Santamaría, V. Segura, L. Sesma, J. Prieto, and F. J. Corrales, "Prohibitin deficiency blocks proliferation and induces apoptosis in human hepatoma cells: molecular mechanisms and functional implications," Proteomics, vol. 10, no. 9, pp. 1609-1620, 2010.

[24] T. Aoe, E. Cukierman, A. Lee, D. Cassel, P. J. Peters, and V. W. $\mathrm{Hsu}$, "The KDEL receptor, ERD2, regulates intracellular traffic by recruiting a GTPase-activating protein for ARF1," $E M B O$ Journal, vol. 16, no. 24, pp. 7305-7316, 1997.

[25] J. Cancino, A. Capalbo, A. Di Campli et al., "Control systems of membrane transport at the interface between the endoplasmic reticulum and the Golgi," Developmental Cell, vol. 30, no. 3, pp. 280-294, 2014.

[26] J. Lippincott-Schwartz, J. G. Donaldson, A. Schweizer et al., "Microtubule-dependent retrograde transport of proteins into the ER in the presence of brefeldin A suggests an ER recycling pathway," Cell, vol. 60, no. 5, pp. 821-836, 1990.

[27] L. G. J. Nijtmans, L. de Jong, M. A. Sanz et al., "Prohibitins act as a membrane-bound chaperone for the stabilization of mitochondrial proteins," The EMBO Journal, vol. 19, no. 11, pp. 2444-2451, 2000.

[28] N. Dean and H. R. B. Pelham, "Recycling of proteins from the Golgi compartment to the ER in yeast," Journal of Cell Biology, vol. 111, no. 2, pp. 369-377, 1990.

[29] M. Capitani and M. Sallese, "The KDEL receptor: new functions for an old protein," FEBS Letters, vol. 583, no. 23, pp. 3863-3871, 2009.

[30] H. R. B. Pelham, "The retention signal for soluble proteins of the endoplasmic reticulum," Trends in Biochemical Sciences, vol. 15, no. 12, pp. 483-486, 1990.

[31] M. J. Lewis and H. R. B. Pelham, "Ligand-induced redistribution of a human KDEL receptor from the Golgi complex to the endoplasmic reticulum," Cell, vol. 68, no. 2, pp. 353-364, 1992.

[32] M. Satoh, K. Hirayoshi, S.-I. Yokota, N. Hosokawa, and K. Nagata, "Intracellular interaction of collagen-specific stress protein HSP47 with newly synthesized procollagen," Journal of Cell Biology, vol. 133, no. 2, pp. 469-483, 1996.

[33] V. Saudek, "Cystinosin, MPDU1, SWEETs and KDELR belong to a well-defined protein family with putative function of cargo receptors involved in vesicle trafficking," PLoS ONE, vol. 7, no. 2, Article ID e30876, 2012.

[34] D. C. Yee, M. A. Shlykov, Å. Västermark et al., "The transporteropsin-G protein-coupled receptor (TOG) superfamily," FEBS Journal, vol. 280, no. 22, pp. 5780-5800, 2013.

[35] Y. Zhai, W. H. M. Heijne, D. W. Smith, and M. H. Saier Jr., "Homologues of archaeal rhodopsins in plants, animals and fungi: structural and functional predications for a putative fungal chaperone protein," Biochimica et Biophysica ActaBiomembranes, vol. 1511, no. 2, pp. 206-223, 2001.

[36] M. L. Villasmil and J. T. Nickels Jr., "Determination of the membrane topology of Arvl and the requirement of the ER luminal region for Arvl function in Saccharomyces cerevisiae," FEMS Yeast Research, vol. 11, no. 6, pp. 524-527, 2011.

[37] D. A. Stroud, S. Oeljeklaus, S. Wiese et al., "Composition and topology of the endoplasmic reticulum-mitochondria encounter structure," Journal of Molecular Biology, vol. 413, no. 4, pp. 743-750, 2011.

[38] F. Faulhammer, G. Konrad, B. Brankatschk, S. Tahirovic, A. Knödler, and P. Mayinger, "Cell growth-dependent coordination of lipid signaling and glycosylation is mediated by interactions between Saclp and Dpmlp," Journal of Cell Biology, vol. 168, no. 2, pp. 185-191, 2005.

[39] Z. Zheng and J. Zou, "The initial step of the glycerolipid pathway: identification of glycerol 3-phosphate/dihydroxyacetone phosphate dual substrate acyltransferases in Saccharomyces cerevisiae," The Journal of Biological Chemistry, vol. 276, no. 45, pp. 41710-41716, 2001.

[40] M. Schuldiner, S. R. Collins, N. J. Thompson et al., "Exploration of the function and organization of the yeast early secretory pathway through an epistatic miniarray profile," Cell, vol. 123, no. 3, pp. 507-519, 2005.

[41] I. Majoul, M. Straub, S. W. Hell, R. Duden, and H.-D. Söling, "KDEL-cargo regulates interactions between proteins involved in COPI vesicle traffic: measurements in living cells using FRET," Developmental Cell, vol. 1, no. 1, pp. 139-153, 2001.

[42] H. Kojima, H. Hashimoto, and K. Yoda, "Interaction among the subunits of Golgi membrane mannosyltransferase complexes of the yeast Saccharomyces cerevisiae," Bioscience, Biotechnology and Biochemistry, vol. 63, no. 11, pp. 1970-1976, 1999.

[43] Y. Zhao, J. Du, B. Xiong, H. Xu, and L. Jiang, "ESCRT components regulate the expression of the ER/Golgi calcium pump gene PMR1 through the Rim101/Nrg1 pathway in budding yeast," Journal of Molecular Cell Biology, vol. 5, no. 5, pp. 336344, 2013.

[44] G. Polier, J. Neumann, F. Thuaud et al., "The natural anticancer compounds rocaglamides inhibit the Raf-MEK-ERK pathway by targeting prohibitin 1 and 2," Chemistry and Biology, vol. 19, no. 9, pp. 1093-1104, 2012.

[45] P. Marra, T. Maffucci, T. Daniele et al., "The GM130 and GRASP65 golgi proteins cycle through and define a subdomain of the intermediate compartment," Nature Cell Biology, vol. 3, no. 12, pp. 1101-1113, 2001.

[46] A. Shevchenko, "Evaluation of the efficiency of in-gel digestion of proteins by peptide isotopic labeling and MALDI mass spectrometry," Analytical Biochemistry, vol. 296, no. 2, pp. 279283, 2001. 

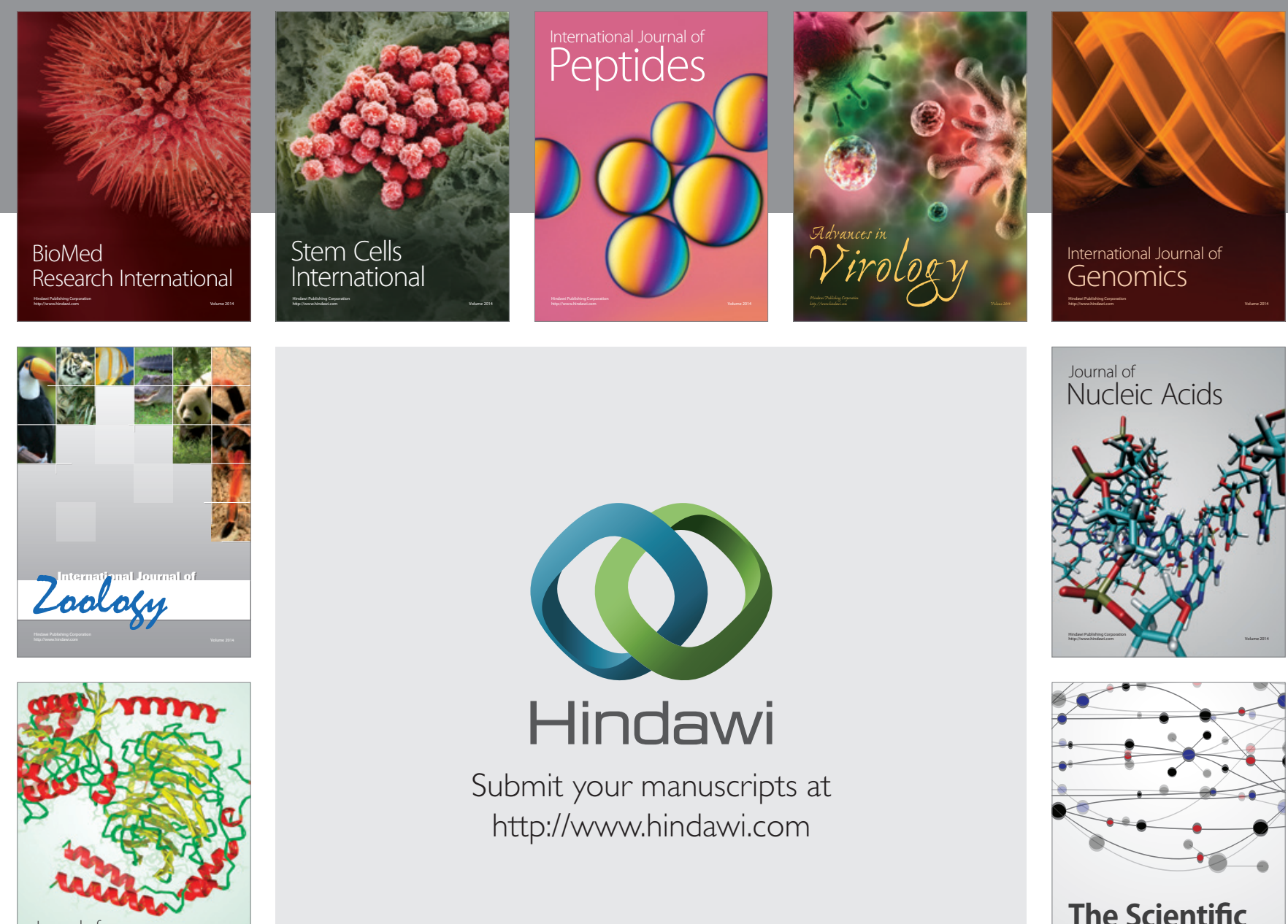

Submit your manuscripts at

http://www.hindawi.com

Journal of
Signal Transduction
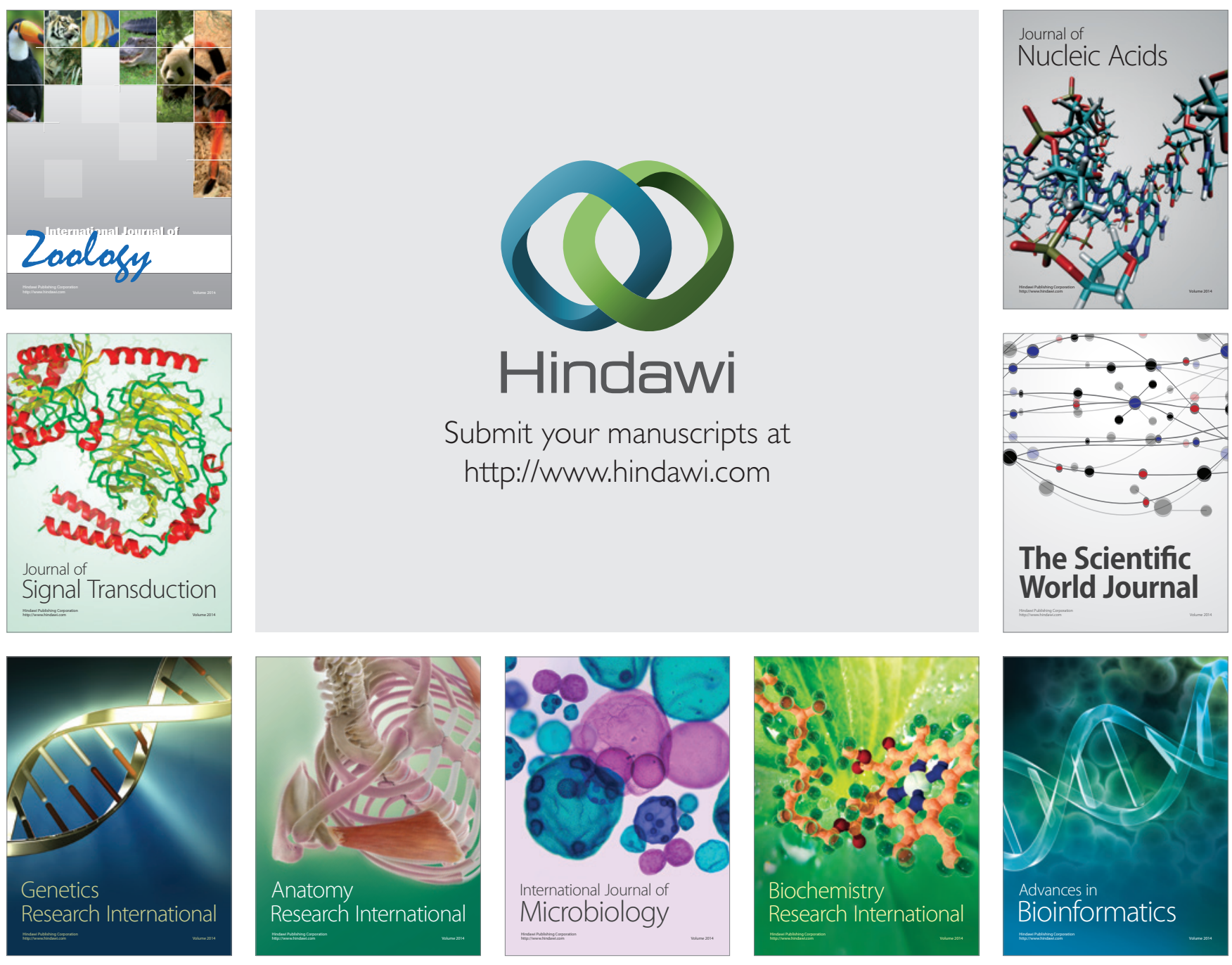

The Scientific World Journal
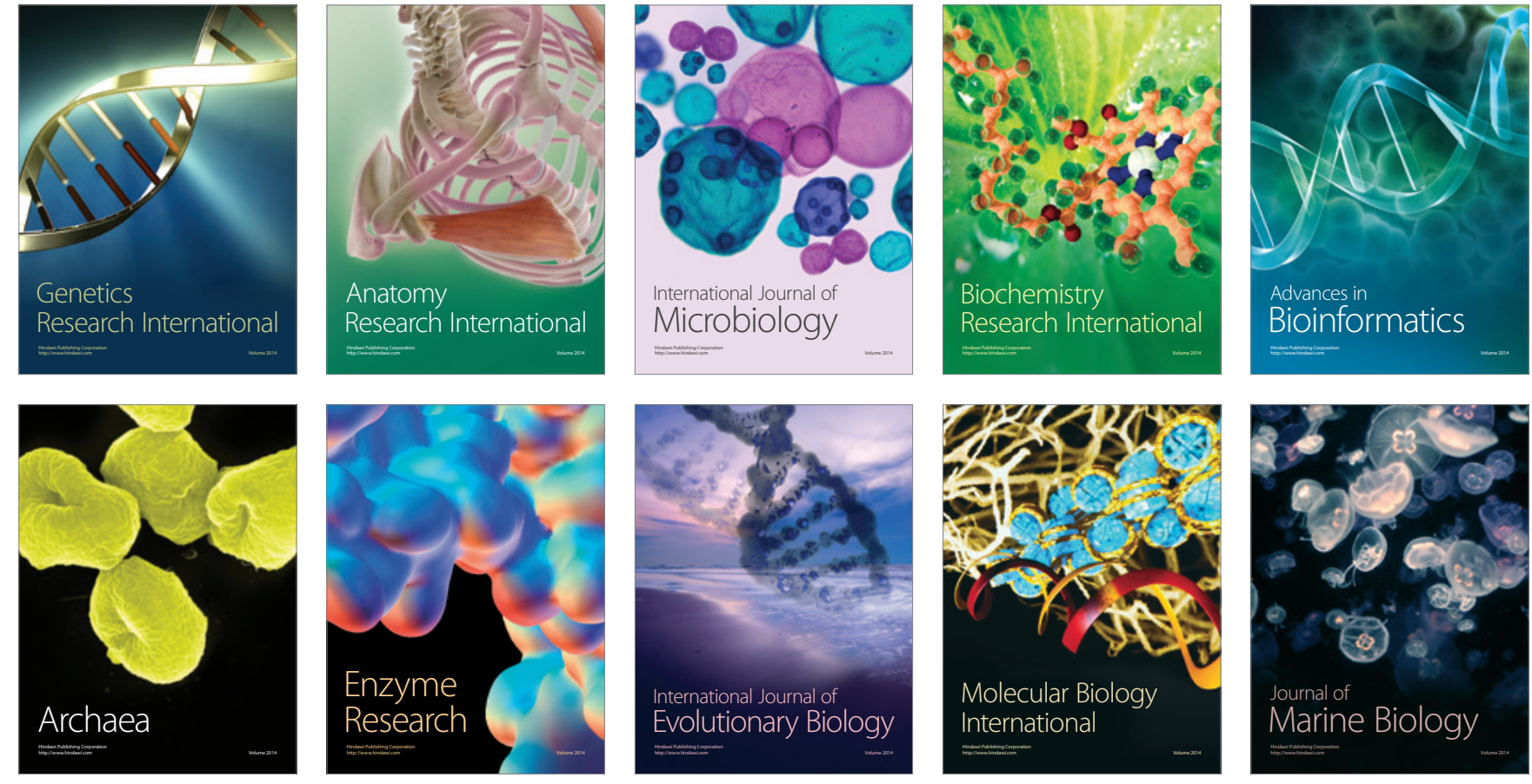